\title{
Influence of Strengthening Rib Location on Temperature Distribution of Heavy Vertical Lathe Worktable
}

\author{
Yanqin Zhang ${ }^{1 *}$, Yao Chen ${ }^{1}$, Zeyang Yu ${ }^{1}$, Yonghai $\mathrm{Li}^{1}$, Weiwei $\mathrm{Li}^{1}$ \\ and Hui Jiang ${ }^{2}$ \\ ${ }^{1 .}$ College of Mechanical \& Power Engineering, Harbin University of Science and \\ Technology, Harbin150080, China \\ 2. Qiqihar CNC Equipment corp, LTD., Qiqihar 161005, China \\ ${ }^{*}$ Yanqin Zhang, yinsi1016@163.com
}

\begin{abstract}
During heavy vertical lathe working, heat caused by oil film friction and self-generated is transmitted to worktable through contact surface between oil film and worktable. That makes temperature distribution of worktable uneven and lead large thermal deformation which can affect the machining accuracy. In this article, the temperature field of worktable with reinforcing plate in different locations is simulated. Based on heat transfer theory and the actual working conditions, convective heat transfer coefficient of worktable and the initial boundary conditions are calculated. The simulation reveals the influence law of reinforcing plate arrangement on temperature distribution of worktable and the optimum position of reinforcing plate is obtained. These results provide a theoretical basis for the structural design of worktable.
\end{abstract} heat

Keywords: strengthening rib, temperature distribution, thermal deformation, convective

\section{Introduction}

In the parts of heavy-duty vertical lathe, the workbench direct contact with machining work piece. Lathe performance directly affects the work piece machining precision and machining efficiency. Workbench is an important part in mechanical processing. Worktable deformation will be a significant impact on machining precision. Thermal deformation accounted for a large part of all the deformation, even the main factors of deformation. Too large of thermal deformation will cause the failure of processing. Therefore the study of the temperature distribution in the workbench has a great practical significance for the product manufacturing.

In recent years, domestic and foreign scholars have study on the vertical lathe workbench and hydrostatic guide-way temperature fields in different degrees. Scholar Jin Jen Wang and So. $\mathrm{H}$ calculated the three-dimensional temperature field and the corresponding deformation field of the precision grinding of the work-piece, using the finite element method to calculate thermal deformation change over time, consistent calculation results and measured data, analysis the data shows the influence of temperature change to parts flatness exceed the influence of external load [1]. Hefei General Machinery Research Institute Yang Dingjun, using the response surface method, combined experimental temperature values to calculate the convective heat transfer coefficient and heat distribution situation, and regard the result as boundary conditions applied to the machine tool guide-way, after using ANSYS analysis, get the 
thermal deformation field which consistent with the measured values, and prove that the use of response surface method and correction of boundary error is feasible [2]. Qiu Jian and Liu Qiwei using infrared temperature measurement technology to measure the temperature distribution in horizontal NC machine tool spindle. They also using laser ranging technology to determine the thermal deformation of the spindle. The data analysis points out that the temperature change is a major factors affecting the deformation of the spindle [3]. In 2007, Chen G.H, Kang Y,Chang Y.P,Peng D.X,studied the influence which the pressure distribution of oil film, the size of the throttle and the geometry of the cavity have on the form of the fluid, solved reynolds equation, and numerically simulated the velocity and pressure in bearing clearances based on the finite element method [4]. Scholars Shao Junpeng, Yu Xiaodong, etc. using many oil pad hydrostatic bearing which is widely used in CNC equipment as the study object,use the numerical simulation method Contrasted the hydrostatic bearing lubricating properties under different oil cavity shape, simulate different oil cavity depth, different speed of the hydrostatic bearing temperature field and verified by experiments [5-13].

This paper summarizes the study that is based on vertical lathe workbench and hydrostatic guide-way performance at home and abroad, using the vertical lathe rotary workbench as the research object, establish workbench convective heat equation, numerical calculations reinforcing plate to rotate at different locations workbench temperature field, get the rotary workbench upper and lower surface temperature and the position of reinforcing plate curve, investigate the law of such vertical lathe rid location influence the workbench temperature distribution, to improve the precision of entire machine.

\section{Heavy-duty Vertical Lathe Workbench Model}

\subsection{Workbench Layout of Three-dimensional Model and Rib}

In this paper, the workbench is the main working parts, which is double column vertical CNC lathe DVT1000 $\times 50 / 150 \mathrm{Q}-\mathrm{NC}$, the workbench entity diameter is $7440 \mathrm{~mm}$, a height of it is $600 \mathrm{~mm}$, the self-weight is $62 \mathrm{t}$, the maximum diameter of work-piece can reach $10000 \mathrm{~mm}$, and the height does not exceed $5000 \mathrm{~mm}$. According to the size of the factory floor measured data, using advanced three-dimensional modeling software UnigraphicsNX4 (hereinafter referred to as UG4) on the bench for three-dimensional modeling, detailed threedimensional model shown in Figure 1, the white part of the oil film contact surface.

The simplified model: The main heat source surface of workbench is the bottom of guideway in worktable rotation contact with oil film. Friction heat and the system heating is mainly through the surface into the workbench. And then through the connected to the surface of steel plate to different parts of the workbench. Because of the workbench, on the base exists 24 oil pad in the same shape, keep a stable rotating speed. Each pad have the same temperature field and deformation field to the workbench after stable work. So the workbench temperature field and thermal deformation field with a pad for a periodic cycle transformation. Take $1 / 24$ of the workbench to calculate can get the deformation field of workbench. The simplified model is shown in Figure 1and Figure 2. 


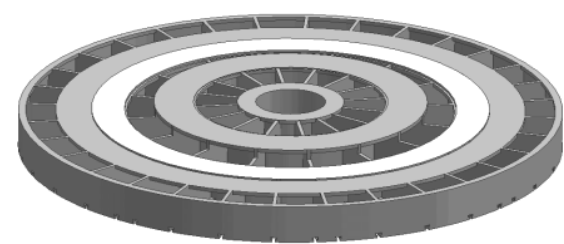

Figure 1. UG Model of Worktable

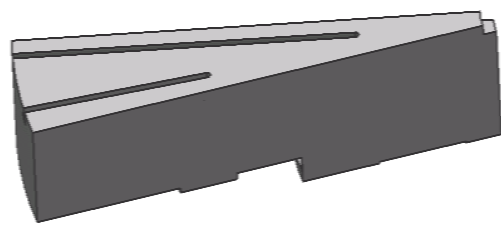

Figure 2. Simplified Model of Worktable

\subsection{Workbench Ribs Arranged}

The internal reinforcing plate plays a role in heat transmission and enhancing the workbench carrying capacity, the number of reinforcing plates and positions change will affect temperature field and deformation field distribution situation, in order to study the internal relations between the reinforcing plates and physical field, will now make the following changes in the reinforcing plates. Figure 3 is no reinforcing plates sectional view of the workbench. In order to study the influence of the circumferential reinforcing plates location to the workbench, the plane plate divided into 11 parts from oil chamber to the center, each of 50mm, 11 positions were added in the circumferential reinforcing plate, Figure 4 is the location where is position 1, Figure 5 is position 6, Figure 6 is a position 11, followed by the oil chamber to the center is $1,2, \ldots 11$.

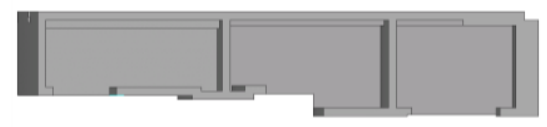

Figure 3. Section Plan of Worktable

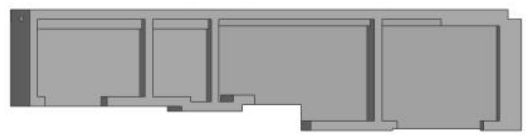

Figure 5. Changed Worktable in Position 6

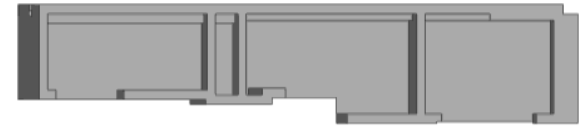

Figure 4. Changed Worktable in Position 1

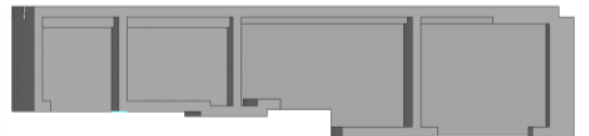

Figure 6. Changed Worktale in Position 11

Gray cast iron accounted for about $80 \%$ in the whole cast iron production that have excellent performance of casting and machining. Due to its own tissue, gray cast iron have excellent damping performance and wear resistance that is good buffering capacity for mechanical vibration. In addition, the external parts gap will have little impact on the fatigue strength of gray cast iron. So gray cast iron widely used in machine tool lathe bed, the base and the creation of the guide-way. This worktable size is bigger. So the worktable must be obtained by casting. And the material is gray cast iron 300.The specific material properties in Table 1.

Table 1. Material Properties of Worktale

\begin{tabular}{cccccccc}
\hline material & $\begin{array}{c}\text { density } \\
\left(\mathrm{Kg} / \mathrm{m}^{3}\right)\end{array}$ & $\begin{array}{c}\text { modulus of } \\
\text { elasticity } \\
(\mathrm{Pa})\end{array}$ & $\begin{array}{c}\text { Poisson } \\
\text { ratio }\end{array}$ & $\begin{array}{c}\text { coefficient } \\
\text { of } \\
\text { expansion } \\
1 /(10-5) \mathrm{K}\end{array}$ & $\begin{array}{c}\text { thermal } \\
\text { conductivity } \\
(\mathrm{W} / \mathrm{m} . \mathrm{K})\end{array}$ & $\begin{array}{c}\text { specific } \\
\text { heat } \\
(\mathrm{J} / \mathrm{Kg} . \mathrm{K})\end{array}$ & $\begin{array}{c}\text { tensile } \\
\text { strength } \\
(\mathrm{Mpa})\end{array}$ \\
\hline HT300 & 7350 & $1.3 \times 10^{11}$ & 0.26 & 1.05 & 48.15 & 523.36 & 245 \\
\hline
\end{tabular}




\section{Convective Heat Transfer Coefficient Calculation}

There are many factors affecting convective heat transfer coefficient, such as the cause of flow and the stable flow status, physical properties of heat transfer fluid and solid, geometry and location of heat transfer surface, whether phase transition occur would caused coefficient changes in the process of heat exchange, the specific manifestation is using different formulas to calculate.

According to the actual production conditions and the workbench geometry, calculate the upper surface forced convection heat transfer coefficient formula, as formula (1).

$$
\mathrm{h}_{u f}=\frac{\lambda N u_{u f}}{r_{x}}
$$

When workbench rotating, in addition to forced convection heat transfer is also accompanied by natural convection, owing to great range of workshops, the space of natural convection heat will not be limited, it becomes a large space natural convection heat. Upper surface natural convection heat transfer coefficient as formula (2).

$$
\mathrm{h}_{u \mathrm{n}}=\frac{\lambda N u_{u n}}{0.9 d_{x}}
$$

In many articles, when considering the mixed convection, always simple summing natural convection and mixed convection, there is a big deviation between this method and the actual situation. In order to more realistically simulate real working conditions, use the following formula to calculate the mixed convection heat transfer coefficient.

$$
N \mathbf{u}_{m}=\sqrt[3]{N u^{3}+N u^{3}}
$$

\section{Temperature Field Simulation Analysis Workbench}

Workbench transfer heat to the upper surface by reinforcing plates, the number of reinforcing plates and the position will affect the amount of heat transfer, thus affect the temperature difference between the upper and lower workbench surfaces. After changing the circumferential reinforcing plates position, through simulation analysis the workbench temperature field, get the impacting data of the temperature change various surface of reinforcing plate position on the workbench. Due to limited space, only lists $20 \mathrm{r} / \mathrm{min}$ speed of the temperature field in position 1.

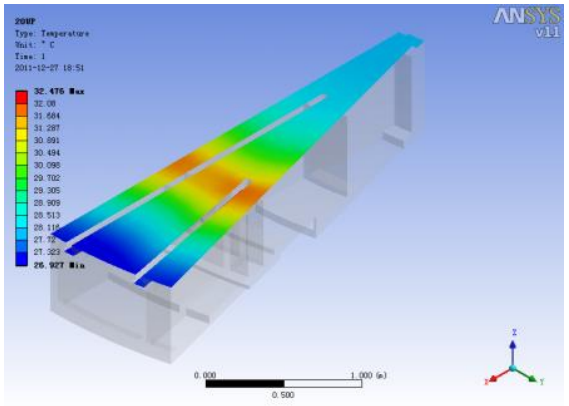

Figure 7. Temperature on the Upper Surface

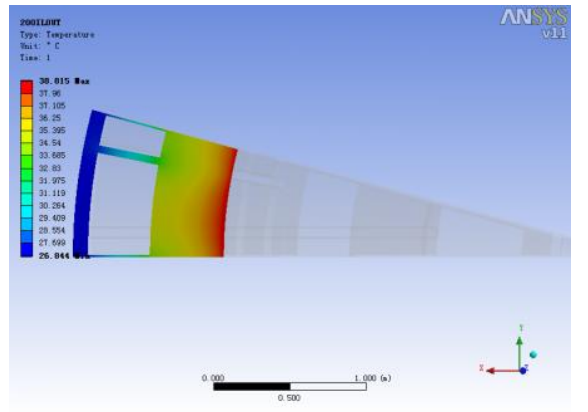

Figure 8. Temperature on the Lower Surface 
When finishing speed 20r/min, the upper and lower surface of reinforcing plates in various positions show the maximum temperature and the difference between the two. The statistics in Table 2, the temperature in position 0 is no circumferential reinforcing plate.

Table 2. Temperature Variation with Chaning Position of Reinforcing Plate

\begin{tabular}{ccccccc}
\hline & 0 & 1 & 2 & 3 & 4 & 5 \\
\hline Upper surface & 31.541 & 2.476 & 32.342 & 32.177 & 32.039 & 31.933 \\
\hline Lower surface & 39.059 & 38.815 & 38.793 & 38.758 & 38.805 & 38.843 \\
\hline $\begin{array}{c}\text { Temperature } \\
\text { difference }\end{array}$ & 7.518 & 6.339 & 6.451 & 6.581 & 6.766 & 6.91 \\
\hline Position & 6 & 7 & 8 & 9 & 10 & 11 \\
\hline Upper surface & 31.852 & 31.791 & 31.738 & 31.697 & 31.663 & 31.635 \\
\hline Lower surface & 38.858 & 38.895 & 38.909 & 38.905 & 38.931 & 38.925 \\
\hline $\begin{array}{c}\text { Temperature } \\
\text { difference }\end{array}$ & 7.006 & 7.104 & 7.171 & 7.208 & 7.268 & 7.29 \\
\hline
\end{tabular}

Concluded from the temperature field of stiffened plates that the workbench have obvious change in upper surface temperature. But in the lower surface temperature and side in both numerical and the distribution have no changed. This is mainly because the lower surface is attached directly to the heat source. The curviness condition between surrounding environment and heat transfer situation. The distribution is mainly determined by the heat source. Under the same rotating speed, heat will not change with the position variation of stiffened plates. So when the circumferential reinforcing plate location changes, the lower surface temperature have no variation. Lateral heat is mainly through the radial stiffened plates heat transfer. The temperature distribution in the circular profile will not be listed.

Crcumferential reinforcing plate major influence the heat of upper surface, the temperature change of the upper surface has a significant role, in order to realize on the relationship between the temperature of upper reinforcing plates surface and the position of the reinforcing plate, using the reinforcing plate position as abscissa, the upper surface temperature as the ordinate, make a graph showing their relationship as Figure 9.

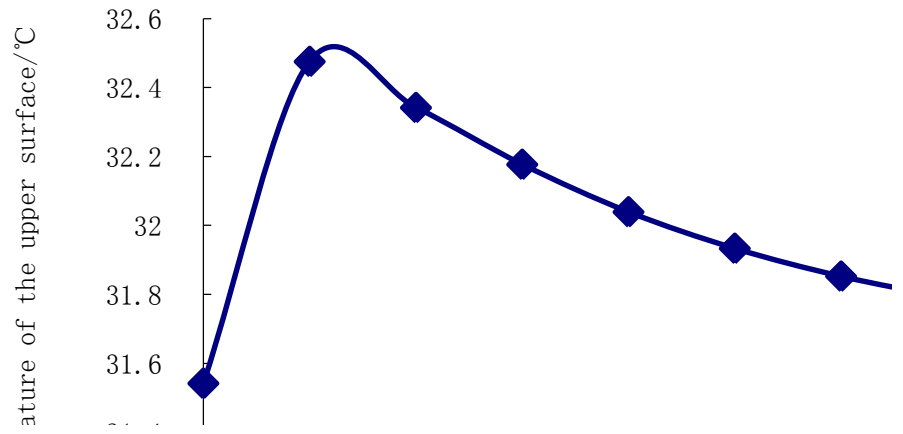

\section{Figure 9. Relationship Curve between Temperature of the Upper Surface and Position}

Because the upper and lower surface temperature difference is one of the main factors in affecting the deformation of the workbench, two different surface temperature will cause the workbench upper and lower surfaces of internal thermal expansion differences, intuitive 
performance is aggravating the thermal deformation phenomenon, so you need to make and analyze a graph showing the relationship between temperature difference and position in Figure 10.

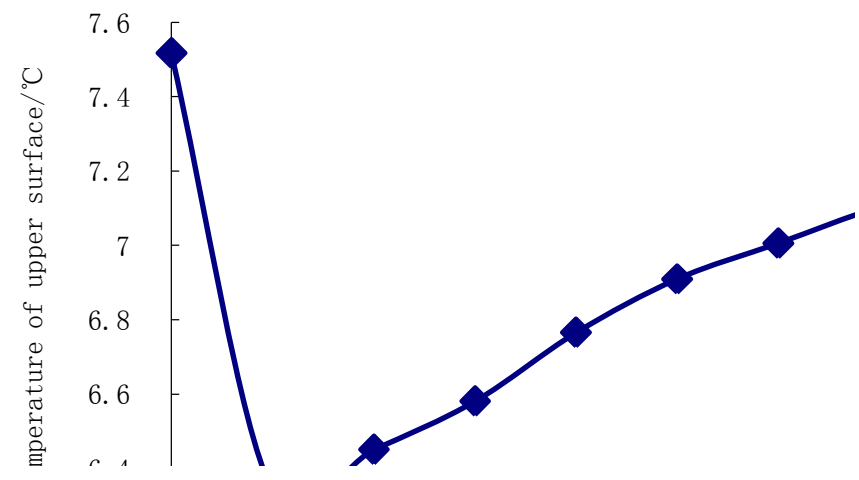

\section{Figure 10. Relationship Curve between Temperature Difference and the Position of Reinforcing Plate}

Concluded from graph 9 and figure 10 that adding circumferential stiffened plates make upper surface temperature rise significantly. Because of the increased heat passed on the surface lead to the temperature rise. But the temperature is not higher than no stiffened plates. Because of lower surface temperature basic maintain stable. So the fluctuation of upper and lower surface temperature range is opposite on the upper surface. Increasing circumferential stiffened plate have the lower temperature range. As the change of location with temperature range gradually increase but no more than any stiffened plates.

\section{Conclusion}

The three-dimensional model of CNC vertical lathe worktable with reinforcing plate in different locations is established. And the convective heat transfer coefficient of the worktable surface is calculated. The equation shows that rotating speed and radius are the main factors affecting heat transfer coefficient.

The temperature field of worktable is analyzed. The results show that there is a temperature difference between top and bottom surfaces of the worktable. That is uneven temperature distribution of the worktable. In order to reduce the worktable temperature difference between the upper and lower surfaces, adding reinforcing plate in the circumferential direction is proposed. The increased circumferential reinforcing plate is analyzed and the temperature field shows that this method plays a positive effect role in homogenization temperature.

\section{Acknowledgements}

This work was Supported by the National Natural Science Funds for Young Scholar of China(No.51005063, 51075106) and Projects of the Special Fund on the Science and Technology Innovation People of Harbin, China (2013RFQXJ086) and supported by the Heilongjiang Postdoctoral Science-Research Foundation(LBH-Q12062). 


\section{References}

[1] J. Jen Wang and H. So, "The effects of thermal deformation on flatness in precision grinding", Journal of Thermal Stresses, vol. 344, (2011), pp. 394-409.

[2] Y. Dingjun, "Study of machine Tool thermal error based on finite element", Mechinery, vol. 388, (2011), pp. 47-58.

[3] Q. Jian, L. Qiwei and L. Xiaofei, "Thermal field distribution of horizontal NC machine tools spindle and its influence on thermal errors of machine tools", Manufacturing Technology \& Machine Tool, vol. 8, (2011), p. 114-118.

[4] G. H. Chen, Y. Kang, Y. P. Chang and D. X. Peng, "Influences of recess geometry and restrictor dimension on flow patterns and pressure distribution of hydrostatic bearings", American Society of Mechanical Engineers Proceedings, vol. 2, (2007), pp. 1045-1053.

[5] S. Junpeng, "The Effect of Oil Cavity Depth on Temperature Field in Heavy Hydrostatic Thrust Bearing", Journal of Hydrodynamics, vol. 23, no. 5, (2011), pp. 676-680.

[6] Y. Xiaodong, "Influence Research of Flow Capacity on Temperature Field of Hydrostatic Thrust Bearing", Applied Mechanics and Materials, vol. 427-429, (2013), pp. 225-229.

[7] Y. Xiaodong, "Simulation on Pressure Field of Gap Oil Film in Constant Flow Hydrostatic Center Frame", Applied Mechanics and Materials, vol. 427-429, (2013), pp. 289-292.

[8] Y. Xiaodong, "Influence Research of Recess Shape on Dynamic Effect of Hydrostatic Thrust Bearing", Applied Mechanics and Materials, vol. 274, (2013), pp. 57-70.

[9] X. Xu and J. Shao, "Simulation on multi-oil-cavity and multi-oil-pad hydrostatic bearings", Applied Mechanics and Materials, vol. 274, (2013), pp. 274-277.

[10] J. Shao and X. Yang, "Simulation and experiment study of heat dissipation of heavy-duty vertical lathe workbench", Key Engineering Materials, vol. 579, (2014), pp. 493-497.

[11] Y. Xiao-Dong, "Lubrication Performance and Velocity Characteristics Multi-pad Constant Current Hydrostatic Thrust Bearing", Journal of Engineering for Thermal Energy and Power, vol. 28, vol. 3, (2013), pp. 296-300.

[12] Y. Xiao-Dong, "Numerical Analysis of Flow Field of Circular Cavity Multi-oil-pad Hydrostatic Thrust Bearing with a Sector-shape Cavity", Journal of Harbin University of Science and Technology, vol. 18, no. 1, (2013), pp. 41-44.

[13] Y. Xiao-Dong, "Research on Pressure Field of Multi-pad Annular Recess Hydrostatic Thrust Bearing", Journal of Donghua University (English Edition), vol. 30, no. 3, (2013), pp. 254-257. 
International Journal of $\mathrm{u}$ - and e- Service, Science and Technology Vol.7, No.1 (2014) 